\title{
6 \\ Agricultural Transformation in the Savannah
}

\author{
Perspectives from the Village
}

Michael Johnson, Nazaire Houssou, Shashidhara Kolavalli, and Peter Hazell

\subsection{Introduction}

Most of the evidence presented in this book about changes in the agricultural sector draws on secondary data and nationally representative household surveys like the GLSS. This chapter seeks to ground the truth of some of the key findings by providing village and farmer perspectives on important changes that have impacted on their livelihoods since the 1980s, and how they have adapted their farming systems and practices. The chapter also addresses several key questions. What were the key factors driving farmers' adaptation decisions, including the roles of changes in population density and the availability of additional land for cultivation, improved access to markets, changing market demands, increased competition for labor from the rural nonfarm economy, and higher wages? Why, despite continuing rural population growth, have farmers generally chosen to adopt technologies and farming practices that increase labor productivity relative to land productivity? Finally, what happens once options for bringing more land into production become exhausted? As discussed in Chapter 4, how well farmers adjust to increasing land scarcity will be critical for the future sustainability of agricultural growth in Ghana.

The study draws on two sources of evidence. First, the results from interviews conducted during 2015 with focus groups and key informants in four representative villages in the transition and Guinea savannah zones. Villages were selected that provide contrasting situations about the availability of additional land. This study is reported in Section 6.2. Second, a farm modeling exercise was undertaken to simulate the changes in farming practices that have 
occurred in the villages since the 1980s to help identify what have been the main drivers of the adaptations farmers have made. This study is reported in Section 6.3.

\subsection{Village and Farmer Perspectives of Change}

Given limited resources, the village study was undertaken in the Guinea savannah and transition zones. ${ }^{1}$ These zones were chosen because they produce the bulk of Ghana's cereal and legume crops (Chapter 4) and because they are also the zones that have experienced the fastest growth in cultivated area since 1992, which is germane to concerns about the sustainability of past patterns of agricultural growth as the land frontier becomes exhausted.

\subsubsection{Selection of Villages}

The study was conducted in two villages in the transition zone and two in the Guinea savannah zones. In each zone, one village was selected that has reached its land frontier (Type I) and one that still has virgin land left (Type II). The villages (Table 6.1) were selected based on discussions with local officials to represent the typical transformations that have occurred in the two zones.

Interviews were conducted in each village during 2015. These involved focus group discussions, as well as individual interviews with selected farmers, village leaders, and local extension and government officials. Interviews followed a loosely structured format in which interviewees were encouraged to identify important changes and to suggest reasons, rather than trying to test many preconceived hypotheses.

Table 6.1. Location and names of the selected villages

\begin{tabular}{llll}
\hline Agroecological zone & District & \multicolumn{2}{c}{ Village } \\
\cline { 3 - 4 } & & Type I & Type II \\
\hline Transition & Ejura-Sekyedumase & Hiawoanwu & $\begin{array}{l}\text { Sekyerekrom } \\
\text { Guinea savannah }\end{array}$ \\
\hline
\end{tabular}

Note: Sekyekrom and Sakpule are also known as Sakiryiakura and Saakpuli, respectively. Source: Authors' village studies.

\footnotetext{
1 This section draws on a more detailed paper by Houssoul et al. (2017).
} 


\subsubsection{Village Characteristics}

Both Type I villages are connected by tarred roads, whereas the Type II villages are connected by sandy/gravel roads. This suggests that land frontier has been reached first in villages that are better connected to urban centers and markets. None of the villages had good roads in the 1980s, and the tarred roads have been constructed since 2000 .

There have been some improvements in education, potable water, and electrification, though not all villages have progressed evenly. All have benefited since 2005 from massive changes in communication with the introduction of mobile phones. In Sekyerekrom, for example, nine out of ten adults have mobile phones.

There have been changes in access to credit as well. During the 1980s and the 1990s, people borrowed from informal sources such as family, relatives, and friends who did not charge any interest. Now they borrow from formal sources paying interest ranging from 30 to 50 percent-even credit from informal family and friends now comes only with interest.

Population sizes have grown in all four villages since the 1980s, often through in-migration. Census data for 2000 and 2010 show that population growth has slowed in recent years (Table 6.2), except in Sapules where it has increased significantly despite this being one of the poorest villages lacking a school and mains electricity. This was basically because of in-migration attracted by the availability of land.

Apart from farming, other sources of income have emerged, such as petty trading, provision of transport services, and firewood and charcoal production. In the two transition zone villages, which are closer to urban centers in the South, youth are also migrating to urban areas to work as electricians, mechanics, and drivers among other occupations.

Table 6.2. Changes in village population, 2000 to 2010

\begin{tabular}{lrr}
\hline Village & \multicolumn{2}{c}{ Census } \\
\cline { 2 - 3 } & $\mathbf{2 0 0 0}$ & $\mathbf{2 0 1 0}$ \\
\hline Hiawoanwu & 2,582 & 2,718 \\
Tindan & 452 & 451 \\
Sekyerekrom & 524 & 523 \\
Sakpule & 186 & 854 \\
\hline
\end{tabular}

Source: Ghana Statistical Service (2000, 2010). 


\subsubsection{Local Perceptions of Change about Farming Practices}

\subsubsection{Land Use}

Farmers report that land was more abundant (and available closer to homesteads) in the 1980s, and cultivated land was allowed to revert to long-term fallow after three to four years of cropping and replaced by clearing virgin or mature fallow land. Today there is little or no virgin land left in any of the villages, and fallow land is also getting scarce, particularly in the Type I villages. In Sekyerekrom, farmers reported that in the 1990s, virgin land accounted for 60 percent of their farmland, but this had declined to 40 percent by the 2000 s, and today there is none left.

There are also more larger farms today than in the 1980s. In the 1980s, only Sekyerekrom had any farms greater 5 acres, but by 2015 half or more of the farms in all four villages were larger than 5 acres (Table 6.3). The emergence of local land constraints has not prevented farmers from expanding their operations; they are expanding by cultivating lands in other villages that still have available land. For example, more than one half of the farmers in Tindang cultivate lands outside their village boundaries. By 2015, there were higher shares of farms in the largest size group in the Type I villages than in the Type II villages. However, this does not mean that many small farms are being consolidated; rather fallow periods are being shortened and farmers are acquiring additional land away from their villages.

Fallowing is still practiced as part of the farming system, but larger farms tend to fallow a smaller portion of their lands than small farms, probably

Table 6.3. Changes in cultivated farm size distribution (\%)

\begin{tabular}{llcrc}
\hline Village & & Size group (acres) & 1980s & 2015 \\
\hline Type I & Hiawoanwu & $1-5$ & 100 & 20 \\
& & $5-15$ & 0 & 30 \\
& \multirow{2}{*}{ Tindang } & $>15$ & 0 & 50 \\
& & $1-10$ & 100 & 30 \\
\multirow{2}{*}{ Type II } & Sekyerekrom & $>-25$ & 0 & 20 \\
& & $1-5$ & 0 & 50 \\
& & $5-15$ & 50 & 30 \\
& \multirow{2}{*}{ Sakpule } & $>15$ & 30 & 40 \\
& & $1-5$ & 100 & 30 \\
& & $5-30$ & 0 & 20 \\
& & $>30$ & 0 & 30 \\
\hline
\end{tabular}

Source: Authors' village studies. 
because they have greater access to tractors. Farmers in one village suggested that smallholders fallow 80 percent of their land compared to 70 and 30 percent on medium- and large-sized holdings.

\subsubsection{Crop Dynamics}

In the 1980s, farmers produced primarily for their own subsistence needs, and the amount of land they could cultivate was limited by the use of hoes and cutlasses for clearing and preparing land. In Tindang, for example, yellow maize and yams were widely grown, though there was no market for either crop at the time. Women in Sakpule indicated that they used to cultivate groundnuts on a single acre of land given to them by their husbands to complement the grains that the males produced for the family pot. Today farm families have greater need for cash to meet the costs of schooling their children and other essentials like mobile phones. To generate more cash income they farm a larger crop area, and hire tractor services from local providers to plow the fields for them. They pay for this service after harvest. Nearly all farm households market some produce today, though the extent of their participation in markets depends on their farm size.

The changes in cropping choices can be summarized as follows:

Transition zone: In Hiawoanwu during the 1980s and 1990s, the crops grown included maize, cowpea, cassava, yam, tomato, groundnut, cotton, and tobacco. In 2010, tomato, cotton, and tobacco had disappeared, and yam, cassava, and groundnuts had declined to subsistence levels. The main cash crops now are maize and cowpeas. A similar trend is observed in Sekyerekrom. Guinea savannah zone: In Tindang, yams and cassava were important crops in the 1980s, but have now disappeared. The main cash crops today are maize, rice, groundnuts, and soybean. A similar trend is observed in Sakpule, where important crops in the 1980s like yams, cassava, millets, and sorghum have all but disappeared today and the main crops today (in order of importance) are soybeans, cotton, rice, and maize.

In general, farmers have moved from root-based subsistence crops (such as yam and cassava) to grain-legume-based crops (such as maize and groundnuts) that have market value. Yams, which require rich soils, are grown immediately after clearing forests. As soil fertility declines, farmers switch to other crops like maize that are more tolerant of the declining soil fertility. The cropping mix has changed from a subsistence-driven system of intercropping based on multiple crops to a mixed subsistence-commercial system based on a few crops, in which commercialized crops are mostly grown as monocrops, such as maize, cowpea, groundnut, and soybean. 
The crop mix also varies by farms size, in part because of labor and capital constraints. For example, in Tindang, small farmers specialize more in laborintensive and capital-extensive crops like soybeans while larger farms specialize more in capital-intensive but labor-extensive crops like rice. The difference in cropping by farm size in Tindang is as follows:

- Large-scale farmers: 50 percent rice, 30 percent maize, and 20 percent groundnut

- Medium-scale farmers: 50 percent maize, 30 percent rice, and 20 percent groundnut, and

- Small-scale farmers: 30 percent maize, 60 percent soybean, and 10 percent groundnut.

In Hiawoanwu, large scale farmers are not cultivating yams because they require special care and labor-intensive husbandry practices.

Farmers explained that their cropping patterns and farm sizes have been influenced by a number of factors, but especially by their household needs for staple foods and cash, soil fertility problems, the location of their lands relative to their houses, and market opportunities. Changes in rainfall patterns have also induced some changes in the crops and varieties that farmers grow.

\subsubsection{Labor Use}

Back in the 1980s, farmers relied on family and communal labor, which was relatively abundant, and adequate to meet their needs. Land preparation and weeding were undertaken manually. Today communal labor has declined significantly, and farmers are cultivating larger areas. This has increased their dependence on hired labor, and at a time when real wages have been rising.

Hired labor has become scarcer and more expensive in the villages, especially during weeding and harvesting operations. Local workers are often insufficient to meet the demand and as a result, migratory workers are helping to fill the gap. In Tindang, laborers migrate from West Mamprusi and Savalegu to the village to offer their services during the farming season. Laborers also migrate from the Guinea savanna zone in the north to the transition zone in the south.

Labor constraints affect different sized farmers differently. Large farms are particularly affected because they need to mobilize more laborers than small farms, and who may not be available at the time needed. On the positive side, large farmers can afford to bring labor from as far as the Northern region, and small farms can access such laborers after they have worked on the large farms. With increasing labor scarcity (and cost), other technologies such as herbicides and tractors for land preparation have emerged as substitutes. 


\subsubsection{Mechanization}

Tractor plowing and maize shelling have increasingly become standard farming practices in the villages. This trend is broadly consistent with regional patterns (Table 6.4). However, access to these technologies differs depending on farm size. Whereas access to tractors is relatively easy for medium- and large-scale farmers, smallholder farmers need to organize to secure tractor services, especially in communities where there is a limited number of locally owned tractors. Some medium- and large-scale farmers also own machines. Increasingly, mechanized farming seems to have shifted labor bottlenecks from land preparation to weeding and harvesting operations.

\subsubsection{Herbicides}

An important labor-saving innovation has been the introduction of herbicides in the villages. The use of herbicides has led to a drastic reduction in the use of hoes, cutlasses, and manual labor for weeding. Herbicide use has also replaced the practice of slash-and-burn cultivation. Weed problems seem to have increased as soil fertility has declined. The uptake of herbicides for land preparation (nonselective) and weed control (selective) occurred in the early 1990s in Hiawoanwu and the early 2000s in Sekyerekrom. Today, the use of herbicides to clear lands before plowing is widespread in the villages. One of the farmers suggested that plowing to clear lands without first applying herbicide lowers germination, limits plant growth, and leads to lower yields. They believe that plowing in dead weeds enriches the soils. However, on-farm weed control by resource-constrained smallholder farmers is still sometimes done manually using family labor. A farmer in Sekyerekrom indicated that in the absence of herbicides, many medium- and small-scale farms would have to scale down their operations.

Table 6.4. Trends in the share of farmers renting mechanical equipment, by farm size

\begin{tabular}{|c|c|c|c|c|c|c|}
\hline \multirow[t]{2}{*}{ Farm category } & \multicolumn{3}{|c|}{ Transition zone } & \multicolumn{3}{|c|}{ Guinea savannah zone } \\
\hline & 1998 & 2005 & 2012 & 1998 & 2005 & 2012 \\
\hline \multicolumn{7}{|c|}{ Percent of farms } \\
\hline$<5$ acres & 0.0 & 4.7 & 7.6 & 6.9 & 3.1 & 12.5 \\
\hline$\geq 5-12$ acres & 4.5 & 2.4 & 9.6 & 6.0 & 4.8 & 25.6 \\
\hline$\geq 12-25$ acres & 0.0 & 12.1 & 18.1 & 12.5 & 6.5 & 38.4 \\
\hline$\geq 25$ acres & 3.7 & 22.5 & 9.0 & - & 7.7 & 35.8 \\
\hline Average & 1.5 & 5.3 & 9.8 & 6.8 & 4.6 & 23.3 \\
\hline
\end{tabular}

Source: Ghana Statistical Service $(1998,2005,2012)$. 


\subsubsection{Fertilizer Use}

Little inorganic fertilizer was used in the 1980s, but today its use is widespread, largely because the fertility of most of the farmed lands has declined. However, farmers use less than the recommended rate of fertilizer for many reasons, including financial constraints, risk management, outdated recommendations, knowledge of their own soils, and the availability of fallow lands. For example, in Sakpule, only 50 percent of farmers in the village applied ammonia in addition to the compound fertilizer, while 75 percent of farmers applied only half of the recommended rate of NPK per acre. Without chemical fertilizers, it seems clear that yields could not have been maintained as lands were more continuously cropped. Organic fertilizers, such as manure are rarely used, except in Tindang, where it is used on a limited scale by cattle owners.

In Hiawoanwu and Sekyerekrom in the transition zone, a standard practice for maintaining soil fertility is the use of a maize-cowpea rotation between major and minor seasons. Likewise in Tindang, farmers practice a soybeanmaize rotation. The nitrogen fixed in the soil by a legume crop like cowpea or soybean benefits the maize crop that follows, enabling farmers to apply less or no chemical fertilizers and to save on their production costs.

\subsubsection{Seeds}

Local and late-maturing varieties of crops were planted in the early 1980s, but many of these have been replaced over time by improved varieties. In Sakpule, farmers indicated that the pattern of rainfall has changed in the past thirty to forty years, and they have switched from local to improved and early-maturing varieties of maize such as Okomasa and Obtampa, and to new crops such as soybean and cotton. Soybean varieties like Jenguma have also been adopted by farmers in the Guinea savannah zone owing to the crop's resistance to shattering, which helps reduce yield losses resulting from late harvesting. Although farmers have adopted improved and early maturing varieties, most of them do not purchase seeds on the market but rely instead on recycled seeds selected from the previous season, a pattern also reported by Ragasa et al. (2013). Furthermore, with declining soil fertility and exhaustion of virgin lands, the major varieties of yam grown have also changed. Modern cultivars are more tolerant of drier conditions and can thrive in less fertile soils, producing big tubers that are consumed domestically but have limited market potential. Amanor and Pabi (2007) also note that yams cultivated with inorganic fertilizers grow to be large but they develop an unpleasant hairy appearance that repels urban consumers. 


\subsubsection{Structure of Farm Input Costs}

The structure of farm input costs has changed over the years in the two zones as shown in Table 6.5. The share of hired labor in total crop expenditure declined between 1998 and 2012, while the shares of fertilizers, herbicides, and insecticides increased. Interestingly, the cost share for mechanical inputs (rented equipment) changed little in the Guinea savannah zone, and remained small in the transition zone despite some increase. The cost share of purchased seeds declined during the same period.

\subsubsection{Productivity}

Farmers were unanimous in their views about yield trends, indicating that land was very fertile in the 1980s, no fertilizer was used, and yields were very good, and at least sufficient to meet their subsistence needs. Currently, in order to obtain comparable yields, farmers indicated that they must apply fertilizer, though they use it sparingly. Table 6.6 also shows that reported yields have been maintained or have increased only slightly, except in Hiawoanwu where farmers claim maize yields have doubled with the use of fertilizer. The generally modest growth in yields is consistent with national data on cereal yields, especially of maize and rice (see Chapter 4 ).

Table 6.5. Selected farm input costs ( $\%$ of total crop expenditure)

\begin{tabular}{|c|c|c|c|c|c|c|}
\hline \multirow[t]{2}{*}{ Input type } & \multicolumn{3}{|c|}{ Transition zone } & \multicolumn{3}{|c|}{ Guinea savannah zone } \\
\hline & 1998 & 2005 & 2012 & 1998 & 2005 & 2012 \\
\hline Hired labor & 43.3 & 39.6 & 31.6 & 18.4 & 23.3 & 13.4 \\
\hline Inorganic fertilizer & 2.8 & 8.5 & 12.5 & 6.9 & 16.2 & 26.2 \\
\hline Seed & 6.2 & 4.9 & 3.2 & 4.2 & 7.7 & 2.3 \\
\hline Insecticides & 0.9 & 2.3 & 2.7 & 1.0 & 1.8 & 3.0 \\
\hline Herbicides & 0.3 & 6.0 & 22.1 & 0 & 0.3 & 12.1 \\
\hline Rented equipment & 0.1 & 0.4 & 1.9 & 11.4 & 4.6 & 10.8 \\
\hline
\end{tabular}

Source: Ghana Statistical Service $(1998,2005,2012)$.

Table 6.6. Trends in maize yields ( $\mathrm{t} / \mathrm{ha})$

\begin{tabular}{|c|c|c|c|c|c|}
\hline & & Hiawoanwu & Sekyerekrom & Tindang & Sakpule \\
\hline \multicolumn{2}{|c|}{ 1980s (without fertilizer) } & 0.8 & 1.0 & 1.0 & 1.3 \\
\hline Current yield & $\begin{array}{l}\text { Without fertilizer } \\
\text { With fertilizer }\end{array}$ & $\begin{array}{l}- \\
1.6\end{array}$ & $\begin{array}{l}0.5 \\
1.3\end{array}$ & $\begin{array}{l}0.4 \\
1.0\end{array}$ & $\begin{array}{l}0.6 \\
1.4\end{array}$ \\
\hline
\end{tabular}

Source: Authors' village studies. 
Table 6.7. Value of agricultural production, income, and consumption expenditures (real US\$)

\begin{tabular}{|c|c|c|c|c|c|c|}
\hline \multirow[t]{2}{*}{ Indicators } & \multicolumn{3}{|c|}{ Transition zone } & \multicolumn{3}{|c|}{ Guinea savannah zone } \\
\hline & 1998 & 2005 & 2012 & 1998 & 2005 & 2012 \\
\hline $\begin{array}{l}\text { Estimated value of agricultural } \\
\text { production (real US\$/ha) }\end{array}$ & 168 & 219 & 353 & 128 & 187 & 297 \\
\hline Share of nonfarm income (\%) & 16.8 & 20.2 & 28.4 & 11.3 & 14.6 & 20.8 \\
\hline $\begin{array}{l}\text { Annual per capita } \\
\text { expenditure (real US\$) }\end{array}$ & 284 & 320 & 734 & 156 & 219 & 512 \\
\hline
\end{tabular}

Source: Ghana Statistical Service (1998, 2005, 2012).

Land productivity (value of production per ha) more than doubled between 1998 and 2012 in both the transition and savannah zones, even though cereal yields did not increase by much (Table 6.7). This reflects changes in the cropping pattern (with increases in crops oriented for the market), as well as changes in real farm gate prices.

\subsubsection{Incomes}

With increases in the average cropped area per farm and land productivity, farm incomes have increased. At the same time, farm households have about doubled their nonfarm sources of income (Table 6.7), which now accounts for 20-30 percent of their household income. The net result has been a substantial increase in household welfare, as measured by real per capita expenditure (Table 6.7). This increased by 260 percent between 1998 and 2012 in the transition zone, and by 328 percent in the Savannah zone.

\subsubsection{Conclusions from the Village Narratives}

Since the 1980s, farmers in the savannah and transition zones have responded to increasing population pressure, changing household needs and expanding market opportunities, by increasing the size of their farms and growing more market-oriented crops. This adjustment has been complicated by an increasing scarcity of virgin land, which has compelled farmers to reduce fallow periods or acquire land in other more distant communities that still have a virgin land frontier. With shortened fallow periods, there has been a decline in soil fertility, and farmers have had to adjust by using inorganic fertilizeressentially to maintain rather than increase yields, introduce soil fertility 
management practices like legume-cereal rotations, and adopt new crops and crop varieties that are more tolerant of less fertile soils and to changing rainfall patterns. Another factor complicating farmers' adaptation has been the increasing cost of labor and growing difficulties in accessing it at critical times of the agricultural season. Farmers have adjusted to this problem by adopting labor-saving technologies like tractors and herbicides, and by growing less labor-using crops.

One result of all these changes is that the composition of outputs has changed from root-based crops for local consumption to grain-legumebased cash crops that are increasingly commercialized. However, because farmers have invested more in labor-saving technologies like mechanization and herbicides than in land-saving technologies like improved seeds and fertilizers, yields have increased only marginally. Yet with the increase in the average cropped area per farm, changes in the crop mix, and an increase in nonfarm incomes, most farm households have managed to make substantial welfare gains since the 1980s, whether measured by the value of agricultural production or household consumption expenditure.

\subsection{A Farm Model Analysis}

In order to better understand the factors driving changes at the farm level and how well farmers have adapted, a mathematical programming model was constructed for farms in a typical village in the transition zone and used to simulate farming practices in 1990, 2000, and 2010. The model is solved for different assumptions about changes in land and labor supplies, technology, wages, and commodity prices, which allows the contributions of different drivers of change to be unraveled.

Three models representing small, medium, and large farms were constructed and results derived for each farm size and for the average village farm. The model assumes rational choice behavior, and in particular that farmers are risk averse and maximize an expected income standard deviation utility function as described in Hazell and Norton (1986). Decisions are made subject to three types of land constraints (virgin, fallow, and continuously cropped lands) and seasonal labor constraints. The total crop area available to the village each year and its allocation between virgin, fallow, and continuously cropped land, are exogenously fixed in the model for each sized farm using data from the village narratives. The model allows farmers to choose which crops to grow and which technologies to use in each of two seasons, where the 
technologies reflect the options for improved seeds, fertilizer, herbicides, and tractors that were available in different decades. Tractor services and seasonal labor can be hired in, and family labor can be hired off farm up to seasonal limits. Some crops, such as vegetables, are excluded from the model due to their small area allocation (primarily to meet subsistence needs) relative to cereals, legumes, and root crops. As in Hazell and Norton (1986), model solutions corresponding to different degrees of risk aversion were compared to actual cropping patterns to select a "best fitting" value of the risk-aversion coefficient.

\subsubsection{Results for Average Farm}

The model was parameterized using data collected during the interviews in Hiawoanwu and Sekyerekrom villages in the transition zone, and from a variety of secondary sources. Additional details of the model and parameter assumptions are presented in the Appendix to this chapter. Table 6.8 presents key results for the average village farm in 1990, 2000, and 2010. This is a weighted average of the results for the small-, medium- and large-sized farms, where the weights are the shares of the three groups in total farms in 1990, 2000, and 2010.

The model results replicate many of the changes in farming practices reported in the village narratives, and provide quantitative estimates about aspects of those practices that could not be elicited during the interviews. Some of the changes were imposed on the model through the resource constraints, most notably the increases in the cultivated farm sizes between 1990 and 2010, and the declining importance of fallow and virgin land and the increasing use of continuously cropped land. In particular, the assumed changes led to the average farm more than doubling its crop area (from 8.8 to 20.7 ha between 1990 and 2010, which was achieved by increasing its continuously cropped area from 2.1 to 13.7 ha, while the fallow and virgin land under cultivation increased modestly; from 4.93 to 5.59 ha and 1.76 to 2.9 ha, respectively, but fell sharply as shares of the total cropped area. Changes in the farm size distribution used to calculate the average farm each year were also exogenous. But most other changes are endogenous to the model. Some key results are as follows:

- Expected farm income more than tripled between 1990 and 2010. This is in line with the increases in annual per capita expenditure reported by the Ghana Statistical Service in Table 6.7. The higher income was achieved without any apparent increase in risk, as measured by the coefficient of variation of income $(\mathrm{CV})$. 
Table 6.8. Model results for the average farm in the representative transition zone village, 1990, 2000, and 2010

\begin{tabular}{|c|c|c|c|c|c|}
\hline & 1990 & 2000 & 2010 & $\begin{array}{c}\text { Ratio } \\
2010 / 2000\end{array}$ & $\begin{array}{c}\text { Ratio } \\
2010 / 1990\end{array}$ \\
\hline Expected income $(\$, 000)$ & 6.2 & 11.1 & 20.2 & 1.82 & 3.25 \\
\hline CV income (\%) & 0.1 & 0.1 & 0.1 & 0 & 0 \\
\hline Cultivated area (ha) & 8.8 & 14.1 & 20.7 & 1.46 & 2.35 \\
\hline \multicolumn{6}{|l|}{ Type land (\%) } \\
\hline Continuously cropped & 24 & 45 & 66 & 1.47 & 2.75 \\
\hline Fallow & 56 & 37 & 27 & 0.73 & 0.48 \\
\hline Virgin & 20 & 18 & 14 & 0.78 & 0.70 \\
\hline \multicolumn{6}{|l|}{ Crop mix (\%) } \\
\hline Yam/cassava & 34 & 22 & 10 & 0.45 & 0.29 \\
\hline Maize based & 66 & 78 & 90 & 1.15 & 1.36 \\
\hline \multicolumn{6}{|l|}{ Crop output (Kg) } \\
\hline Cassava & 20,002 & 9,024 & 10,652 & 1.18 & 0.53 \\
\hline Cowpeas & 0 & 7,307 & 17,324 & 2.37 & - \\
\hline Groundnuts & 6,220 & 5,163 & 3,969 & 0.77 & 0.64 \\
\hline Maize & 12,794 & 33,278 & 53,607 & 1.61 & 4.19 \\
\hline Yams & 17,860 & 9,191 & 10,078 & 1.10 & 0.56 \\
\hline \multicolumn{6}{|l|}{ Labor use (days) } \\
\hline Family labor & 577 & 776 & 878 & 1.13 & 1.52 \\
\hline Hired labor & 690 & 630 & 1,138 & 1.81 & 1.65 \\
\hline Total labor & 1,267 & 1,406 & 2,016 & 1.43 & 1.59 \\
\hline Total labor (days/ha) & 145 & 100 & 97 & 0.97 & 0.67 \\
\hline \multicolumn{6}{|l|}{ Labor and land productivity } \\
\hline Total labor (\$/day) & 3.0 & 5.5 & 8.0 & 1.45 & 2.67 \\
\hline Land productivity (\$/ha) & 626 & 695 & 886 & 1.27 & 1.42 \\
\hline \multicolumn{6}{|l|}{ Technology adoption } \\
\hline Fertilizer (kg/ha) & 16.4 & 28.0 & 33.9 & 1.21 & 2.07 \\
\hline Total fertilizer (kg) & 143 & 396 & 703 & 1.77 & 4.92 \\
\hline Fertilizer (\% maize area) & 49 & 63 & 82 & 1.32 & 1.67 \\
\hline Land under tractors (\%) & 7 & 45 & 86 & 1.91 & 12.29 \\
\hline Seeds (\% farm area) & 65 & 100 & 100 & 1.00 & 1.54 \\
\hline
\end{tabular}

Source: Authors' model results.

- As in the farm narratives, there is a marked shift from a root-based cropping system based on yams and cassava to a grain-based cropping system based on maize and legumes. The preferred legumes are groundnuts and cowpeas.

- The output of cassava, groundnuts, and yams declined by 47,36 , and 44 percent, respectively, between 1990 and 2010 while there was a fourfold increase in maize production, and cowpeas production went from zero to $17,324 \mathrm{~kg}$. 
- Total labor use per hectare declined by one third due to greater use of labor-saving technologies and less labor-intensive crops, but total labor use on the farm increased by 60 percent, mainly because of the increased cropped area. Family and hired labor use increased by 52 and 65 percent, respectively, but all the increase in the use of hired labor occurred between 2000 and 2010 .

- The percentage of the cropped area plowed with tractors increased from 7 percent in 1990 to 86 percent in 2010.

- Fertilizer use per hectare doubled between 1990 and 2010, but its use still remained moderate at $33.9 \mathrm{~kg} / \mathrm{ha}$ in 2010 . Total fertilizer use increased much more, by about 400 percent, because of the increased crop area as well as more intensive use of fertilizer. Much of the fertilizer is applied to the maize crop, 82 percent of which was fertilized in 2010, up from 49 percent in 1990.

- The use of improved maize seeds increased from 65 percent of the maize area in 1990 to 100 percent in 2000, and remained at full adoption through 2010. Even higher yields might have been obtained with hybrid maize, but this was not included as an option in the model because hybrid seeds were virtually unattainable in the study area over the period modeled.

- While labor productivity increased by 167 percent between 1990 and 2010 , land productivity (income per hectare) increased by a more modest 42 percent. These increases translate into annualized growth rates of 1.7 percent for labor productivity and 3.9 percent per annum for land productivity. The growth in land productivity is primarily the result of a larger cropped area, a shift towards higher value crops, and the adoption of labor-saving technologies, as also reported from the village narratives.

\subsubsection{Differences by Farm Size}

Table 6.9 and Figure 6.1 highlight some important differences in the results by farm size.

Small farms increased their cropped area by 92 percent between 1990 and 2010, compared to 51 percent for medium-sized farms and 27 percent for large farms. These changes were exogenous to the model, but importantly small farm income increased proportionally more than the incomes of the medium and large farms; by 222 percent verses 134 percent and 85 percent, 
Table 6.9. Selected model results by farm size group, representative village in the transition zone, 1990, 2000, and 2010

\begin{tabular}{|c|c|c|c|c|c|c|c|c|c|}
\hline \multirow[t]{2}{*}{ Variable } & \multicolumn{3}{|c|}{ Small farm } & \multicolumn{3}{|c|}{ Medium farm } & \multicolumn{3}{|c|}{ Large farm } \\
\hline & 1990 & 2000 & 2010 & 1990 & 2000 & 2010 & 1990 & 2000 & 2010 \\
\hline Expected income $(\$ 000)$ & 2.2 & 4.0 & 7.1 & 5.6 & 7.9 & 13.1 & 18.6 & 23.8 & 34.5 \\
\hline CV income (percent) & 19 & 16 & 9 & 17 & 17 & 9 & 11 & 13 & 7 \\
\hline Cropped area (ha) & 1.3 & 1.8 & 2.5 & 6.4 & 7.9 & 9.7 & 33.0 & 37.1 & 41.8 \\
\hline \multicolumn{10}{|l|}{ Crop mix (percent) } \\
\hline Yam/cassava & 42.1 & 44.8 & 23.8 & 30.2 & 12.0 & 8.7 & 17.0 & 1.2 & 1.5 \\
\hline Maize based & 57.9 & 55.2 & 76.2 & 69.8 & 88.0 & 91.3 & 83.0 & 98.8 & 98.5 \\
\hline \multicolumn{10}{|l|}{ Labor use (days) } \\
\hline Total labor & 241 & 306 & 323 & 1,028 & 982 & 991 & 4,519 & 3,335 & 3,970 \\
\hline Hired & 0 & 0 & 0 & 173 & 0 & 114 & 3,260 & 2,099 & 2,744 \\
\hline Total (days/ha) & 185 & 170 & 129 & 160 & 124 & 102 & 137 & 90 & 95 \\
\hline \multicolumn{10}{|l|}{ Technology adoption } \\
\hline Fertilizer (kg/ha) & 14.5 & 20.7 & 28.6 & 17.5 & 29.2 & 34.2 & 20.7 & 37.0 & 36.9 \\
\hline Total fertilizer (kg) & 19 & 37 & 71 & 112 & 231 & 332 & 685 & 1,374 & 1,544 \\
\hline Fertilizer (\% maize area) & 41 & 38 & 62 & 54 & 78 & 84 & 71 & 98 & 97 \\
\hline Land under tractors (\%) & 0 & 5 & 60 & 8 & 47 & 91 & 27 & 98 & 99 \\
\hline Seeds ( $\%$ of farm area) & 80 & 100 & 100 & 58 & 100 & 100 & 28 & 100 & 100 \\
\hline
\end{tabular}

Source: Authors' model results.

respectively. Although small farms followed medium and large farms in shifting from a root-based to a maize-based cropping system, the shift was more muted, in part because of their own consumption needs for these crops.

Total labor use increased by 34 percent (from 241 to 323 days) on small farms between 1990 and 2010, but declined by 4 percent and 12 percent, respectively, on medium and large farms. This reflects changes in the labor intensity of their different cropping patterns and differences in the uptake of tractor mechanization. Small farms also use more labor per hectare than medium and large farms in all three years. Hired labor is used mostly on large farms but their total use fell by 16 percent between 1990 and 2010 . Small farms do not use any hired labor in the model results, and medium-sized farms used only moderate amounts. Small farms use less fertilizer per hectare than larger farms in all three years, but they also fully adopt improved maize seeds by 2000 .

Finally, while there is a more than doubling of labor productivity for all sized farms, land productivity (income per hectare) increases more modestly, by 53 percent, 46 percent, and 45 percent for small, medium, and large farms. These translate into annualized growth rates in labor productivity of 


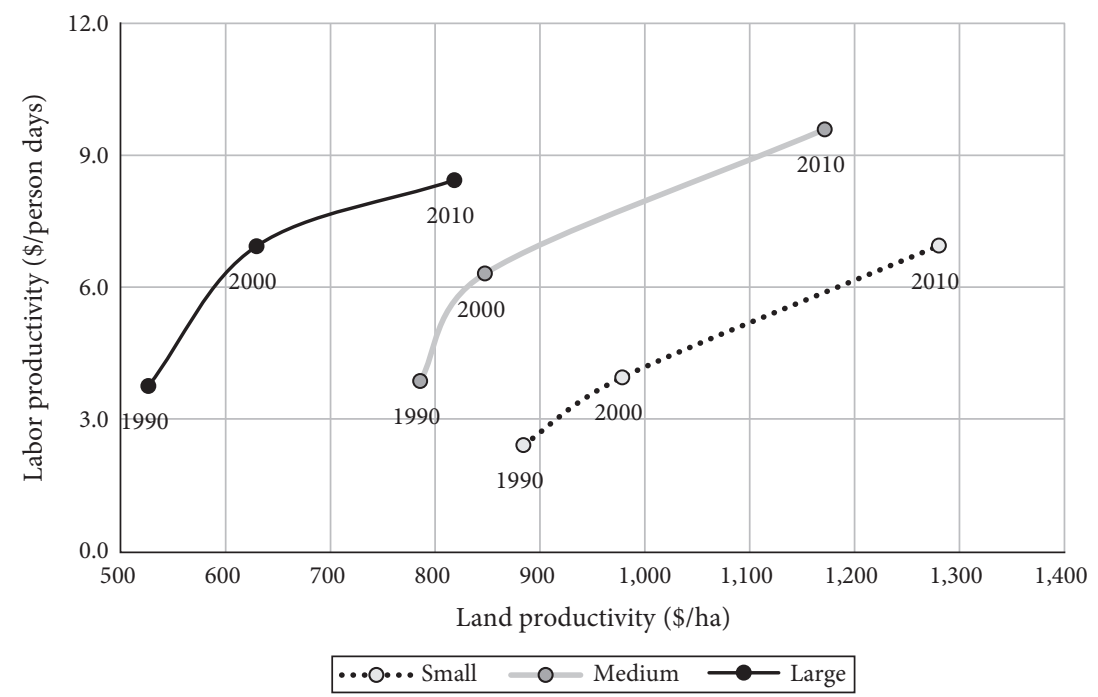

Figure 6.1. Changes in labor and land productivity by farm size, representative village in the transition zone, 1990-2010 Source: Authors' model results.

7.8, 5.6, and 4.5 percent for small, medium, and large farms, respectively, over 1990-2010, but only about 2 percent per annum in land productivity for all farms. As might be expected, smaller farms experience higher values of land productivity than medium and large farms, as illustrated in Figure 6.1.

\subsubsection{A Decomposition Analysis of the Changes, 1990-2010}

The model was used to identify the contributions of different drivers of change between 1990 and 2010 for each farm size group using a decomposition analysis. Specifically, model simulations were undertaken to decompose changes in key endogenous variables like expected income, input use, crop choice and production into parts due to exogenous changes over 1990 to 2010 in available land and improved seeds, and changes in wages, input and output prices, and a residual measuring interactions between these components. This was done by first solving the 1990 and 2010 models to calculate the total change in key endogenous variables, and then solving the 1990 model with 2010 land constraints and everything else set at 1990 values; solving again for 2010 seeds with everything else set at 1990 values; solving again for 2010 wages 
with everything else set at 1990 values; etc. Then for each endogenous variable of interest calculate:

$\mathrm{Y}_{2010}=\mathrm{Y}_{1990}+\mathrm{Y}_{1990}$ (given 2010 land) $+\mathrm{Y}_{1990}$ (given 2010 wage) $+\mathrm{Y}_{1990}$ (given 2010 seeds) $+\mathrm{Y}_{1990}$ (given 2010 price ratios) + Residual (equals interaction terms).

Where the residual is calculated as the difference to balance the equation. The results can then be used to assess the relative importance of changes in the exogenous variables in explaining the changes between 1990 and 2010 .

Table 6.10 shows the decomposition results. Some key points are as follows:

- The exogenous increase in farm sizes between 1990 and 2010 accounts for about 10 percent of the increase in expected incomes for all sized farms. Increases in farm size are also an important driver of the increases in total labor use for all sized farms, and for hired labor on medium and large farms. Increases in farm size are also an important driver of fertilizer use for all sized farms.

- Increases in farm size had a negligible impact on the use of tractor plowing. The latter was more affected by increases in the wage rate and, in the case of large farms, by reductions in input (presumably herbicide) costs.

- Increases in wages acted to reduce labor use on all sized farms, and encouraged greater use of tractor plowing. Wage increases also had a positive impact on the incomes of small and medium-sized farms, but a negative impact on the incomes of large farms. This is because large farms are net buyers of labor, whereas small and medium farms sell more labor off farm over the year than they hire in.

- Improved seeds made an important contribution to incomes, especially for medium and large farms, but acted to reduce total fertilizer use. This is surprising; seeds seem to be used as a substitute for fertilizer rather than as a complementary input, perhaps because they are used on more fertile land.

- Changes in output prices contributed little to incomes, but encouraged greater use of fertilizer, a pattern that was reinforced by reductions in input prices. Changes in input prices also encouraged greater mechanization and reduced labor use. This is partly the impact of less costly herbicides. 
Table 6.10. Decomposition of changes in selected variables by farm size group, representative village in the transition zone, 1990-2010

\begin{tabular}{|c|c|c|c|c|c|c|c|c|}
\hline \multirow[b]{2}{*}{$\begin{array}{l}\text { Endogenous variable (by farm } \\
\text { type) }\end{array}$} & \multicolumn{7}{|c|}{ Percentage share of 2010 value attributed to } & \multirow[b]{2}{*}{$\begin{array}{l}2010 / 1990 \\
\text { value }\end{array}$} \\
\hline & 1990 value & $\begin{array}{l}\text { Change } \\
\text { in land }\end{array}$ & $\begin{array}{l}\text { Change } \\
\text { in wages }\end{array}$ & $\begin{array}{l}\text { Change } \\
\text { in seeds }\end{array}$ & $\begin{array}{l}\text { Change in } \\
\text { output prices }\end{array}$ & $\begin{array}{l}\text { Change in } \\
\text { input prices }\end{array}$ & $\begin{array}{l}\text { Interaction } \\
\text { terms }\end{array}$ & \\
\hline \multicolumn{9}{|l|}{ Expected income (\$) } \\
\hline Small farm & 31.5 & 11.6 & 41.1 & 9.6 & 0.1 & 1.6 & 4.4 & 3.2 \\
\hline Medium farm & 42.8 & 13.6 & 8.7 & 23.0 & 3.1 & 4.9 & 3.9 & 2.3 \\
\hline Large farm & 53.9 & 10.8 & -25.1 & 45.8 & 5.0 & 13.3 & -3.6 & 1.9 \\
\hline \multicolumn{9}{|l|}{ Total fertilizer use (kg) } \\
\hline Small farm & 26.4 & 37.4 & 18.0 & -9.3 & 14.5 & 38.8 & -25.8 & 3.8 \\
\hline Medium farm & 33.7 & 22.4 & -12.4 & -13.9 & 10.0 & 29.0 & 31.3 & 3.0 \\
\hline Large farm & 44.4 & 16.3 & -25.7 & -10.6 & 5.3 & 35.9 & 34.4 & 2.3 \\
\hline \multicolumn{9}{|l|}{ Tractorized land area (ha) } \\
\hline Small farm & 0.0 & 0.0 & 42.5 & 0.0 & 0.0 & 3.3 & 54.2 & - \\
\hline Medium farm & 6.1 & -3.1 & 40.7 & -2.9 & -5.5 & 3.2 & 61.3 & 16.3 \\
\hline Large farm & 21.3 & 3.5 & 28.0 & -9.4 & -9.0 & 34.2 & 31.4 & 4.7 \\
\hline \multicolumn{9}{|l|}{ Labor use (days)_family } \\
\hline Small farm & 74.6 & 54.3 & -31.3 & 4.0 & -11.3 & -9.5 & 19.2 & 1.3 \\
\hline Medium farm & 97.5 & 22.7 & -25.9 & -0.9 & 11.0 & -4.5 & 0.0 & 1.0 \\
\hline Large farm & 102.6 & 0.0 & -27.1 & 0.0 & 9.3 & -12.5 & 27.7 & 1.0 \\
\hline \multicolumn{9}{|l|}{ Labor use (days)-Hired } \\
\hline Small farm & 0.0 & 0.0 & 0.0 & 0.0 & 0.0 & 0.0 & 0.0 & 1.0 \\
\hline Medium farm & 151.7 & 251.2 & -138.7 & 82.9 & -134.0 & -32.2 & -81.0 & 0.7 \\
\hline Large farm & 118.8 & 35.3 & -92.2 & 31.4 & -8.9 & -39.9 & 55.4 & 0.8 \\
\hline \multicolumn{9}{|l|}{ Labor use (days)_Total } \\
\hline Small farm & 75.9 & 55.2 & -31.9 & 4.1 & -11.5 & -9.7 & 19.5 & 1.3 \\
\hline Medium farm & 84.8 & 40.1 & -31.8 & 7.2 & -4.7 & -6.2 & -7.6 & 1.0 \\
\hline Large farm & 100.2 & 21.5 & -63.5 & 19.1 & -2.9 & -27.7 & 41.3 & 0.9 \\
\hline
\end{tabular}

Source: Authors' model results. 


\subsection{Conclusions}

The village narratives and the farm model results tell a consistent story of change since the 1980s in the savannah and transition zones. Farmers have responded rationally to increasing population pressure, changing household needs and expanding market opportunities, by increasing the size of their farms and growing more market-oriented crops. This adjustment has been complicated by an increasing scarcity of virgin land, which has compelled farmers to reduce fallow periods or acquire land in other more distant communities that still have a virgin land frontier. With shortened fallow periods there has been a decline in soil fertility and farmers have had to apply more inorganic fertilizer to maintain rather than increase yields, introduce soil fertility management practices like legume-cereal rotations, and adopt new crops and crop varieties that are more tolerant of less fertile soils and to changing rainfall patterns. Also, higher wages and difficulties in accessing hired labor at critical times of the agricultural season have led farmers to adopt labor-saving technologies like tractors and herbicides, and to switch to crops that require less labor.

As a result, the composition of farm output has changed from root-based crops for local consumption to grains and legumes (especially maize, cowpeas, and groundnuts) that are increasingly commercialized. Given the emphasis on labor-saving technologies like mechanization and herbicides, labor productivity has risen faster than land productivity, and yields of many crops have increased only marginally. However, because of the increase in the average cropped area per farm, changes in the crop mix, and some increase in nonfarm incomes, most farm households have managed to substantially increase their incomes since the 1980s, whether measured by income, the value of agricultural production, or household consumption expenditure.

Although farmers have adjusted to increasing land scarcity, it is not clear that they have found a sustainable solution for future agricultural growth. They are still exploiting remaining opportunities to shorten fallows and offset declining soil fertility with fertilizers and crop rotations, and seeking additional land in other villages. But there is little evidence that they are successfully switching to yield enhancing technologies that will be essential for future agricultural growth. This is true even in the villages that have already reached their land limit. Such intensification may require a more proactive policy agenda, especially promoting hybrid seeds and the like. We return to these issues in Chapter 10. 


\section{Appendix 6A: Description of the Ghana Farm Model}

\section{The Model}

The model was developed using the general algebraic modeling system, or GAMS (Brooke et al. 1998), using nonlinear programming approaches. The choice variables in the model (to be capitalized) include land area $\left(X_{i j k}\right)$ allocated by farmer type $i$ (small, medium, and large) to activities $j$ (by crop and technology type) and land type $k$. Labor can be own family labor $\left(L_{i t}^{f i n}\right)$ and/or hired labor $\left(L_{i t}^{h}\right)$ at the going wage rate $\left(w_{t}\right)$. Additionally, because we assume the existence of a labor market, we also permit each farmer type to sell their own labor at any time of the year $\left(L_{i t}^{\text {fout }}\right)$ but at a fraction of the going wage rate $\left(w_{t}^{*}\right)$. Five major crop rotation activities $j$ are included with assumed area allocation to those activities. Because of bimodal rainy seasons in the Ejura area, farmers typically rotate their cropping activities between legumes and cereals (in this case, cowpeas, groundnuts, and maize). The exceptions are root crops, such as yam and cassava, as these are single annual crops. Table 6A.1 summarizes these crop activities, as well as a description of the various parameters, indices, and endogenous variables defined in the model.

Mathematically, the objective for each average farmer type $i$ is represented by $z_{i}$ in equation 1 below-to maximize net profits $\left(\pi_{i}\right)$ minus its standard deviation $\left(\sigma_{i}\right)$ across activities $\left(X_{i j k}\right)$ multiplied by a risk parameter $(\rho)$ whose values can be adjusted to reflect the degree of risk aversion among farmers in each location. Specifically:

$$
\operatorname{Max} z_{i}=\pi_{i}-\rho_{i} \sigma_{i}, \forall i
$$

Where:

$$
\pi_{i}=\sum_{j} \sum_{k}\left[\mu_{i j k}-\sum_{t} c_{i j t} X_{i j k}(1+\tau)\right]+\sum_{t}\left(w_{t}^{*} L_{i t}^{o u t}-w_{t} L_{i t}^{i n}\right), \forall i
$$

[Expected income]

$$
\sigma_{i}=\sqrt{v_{i}}, \text { and } v_{i}=\sum_{j} \sum_{k} \sum_{j^{\prime}} \sum_{k^{\prime}} \operatorname{cov}_{j k j^{\prime} k^{\prime}}
$$

[Standard deviation of gross margins]

And where:

$$
\mu_{i j k}=\frac{1}{N} \sum_{n=1}^{N} p_{i j}^{n} y_{i j l}^{n}, \forall i j
$$

[Gross margins by crop activity]

$$
v_{j k j^{\prime} k^{\prime}}=\frac{1}{N} \sum_{n=1}^{N}\left(p_{i j}^{n} y_{i j k}^{n}-\mu_{i j k}\right)\left(p_{i j^{\prime}}^{n} y_{i j^{\prime} k^{\prime}}^{n}-\mu_{i j^{\prime} k^{\prime}}\right), \forall i
$$

[Variance-covariance of gross margins by crop activity]

For the risk parameter values $\left(\rho_{i}\right)$ in equation (1), we use the risk premium value of $\rho_{i}=1.485$ for all farmer types (small, medium, and large). This was derived as the bestfitting value for aligning the model results with the actuals as revealed through the farmer narratives using the approach suggested by Hazell and Norton (1986). The model considers 
Table 6A.1. Summary description of model parameters and variables

a) Indices and subscripts

$\begin{array}{ll}\text { Index } & \text { Description } \\ i & \text { Farmer type } i=\text { small, medium, and large } \\ j & \text { Crop rotations and technology type, } j=\text { CPMZ, GNMZ, MZCP, MZGN, and } \\ & \text { YMCS with improved or traditional variety seed, mechanized with chemicals, } \\ & \text { with fertilizer or not. YMCS=yam-cassava single intercrop. For the maize- } \\ & \text { based crops, the crop activities are sequenced by the bimodal season (1st crop } \\ & \text { is cultivated in the major season, and 2nd in the minor season later in the year } \\ & \text { as a rotation on the same area plot-see Figure } 6 \text { A.1 below): CPMZ=cowpea- } \\ & \text { maize rotation; GNMZ=groundnut-maize rotation; MZCP=maize-cowpea } \\ & \text { rotation; MZGN=maize-groundnut rotation. Technology type are two seed } \\ & \text { varieties (traditional or local and improved), inorganic fertilizer (with four } \\ & \text { application rates: } 1 / 4,1 / 2,3 / 4, \text { and full, based on a maximum recommended } \\ & \text { dosage), and tractor and chemical use for cultivating and clearing land. } \\ & \text { Land type } k=\text { continuously cropped, previously fallowed, and cleared virgin } \\ & \text { land } \\ & \text { Primes of indices of } j \text { and } k . \\ j^{\prime}, k^{\prime} & \text { Seasons by month of the year, } t=1, \ldots, 12 \\ t & \text { Years within each decade } n=1, \ldots, \mathrm{N}(\mathrm{N}=10) \\ n & \end{array}$

b) Exogenous or fixed parameters

\begin{tabular}{|c|c|}
\hline Parameter & Description \\
\hline$\rho_{i}$ & Risk parameter of farmer type $i, 0<\rho_{i} \leq 1.65$ \\
\hline$w_{t}$ & Seasonal going wage rate (monthly), $t=1, \ldots, 12$ \\
\hline$w_{t}^{*}$ & $\begin{array}{l}\text { Seasonal wage earned for hiring out family labor (as a fraction of } w_{t} \text { ), } \\
t=1, \ldots, 12\end{array}$ \\
\hline$p_{i j}^{n}$ & $\begin{array}{l}\text { Annual average commodity prices at farm gate for each decade, } \mathrm{n}=1, \ldots, \mathrm{N} \\
(\mathrm{N}=10)\end{array}$ \\
\hline $\begin{array}{l}y_{i j k}^{n} \\
\tau\end{array}$ & $\begin{array}{l}\text { Annual average commodity yields and by land type } k, \mathrm{n}=1, \ldots, \mathrm{N}(\mathrm{N}=10) \\
\text { Average interest rate }\end{array}$ \\
\hline$c_{i j t}$ & $\begin{array}{l}\text { Per hectare cost of purchasing inputs: seeds, fertilizer, chemicals, and the use } \\
\text { of a tractor }\end{array}$ \\
\hline$f_{i t}$ & Total adult equivalent family labor available each month $t$ for farmer type $i$. \\
\hline$\alpha_{j k t}$ & $\begin{array}{l}\text { Per hectare labor requirements for land preparation, planting, weeding, } \\
\text { applying chemicals and operating a tractor or each activity } j \text { and land type } k\end{array}$ \\
\hline$\alpha_{j k t}^{h}$ & $\begin{array}{l}\text { Per hectare labor requirements for harvesting of crop activity } j \text { and with land } \\
\text { type } k \text { in month } t \text { and as a function of average yield, i.e., } a_{j t}^{h}=f\left(\bar{y}_{i j k}\right) \text { for a } \\
\text { month of harvesting. }\end{array}$ \\
\hline
\end{tabular}

c) Endogenous or choice variables

Parameter Description

$\pi_{i} \quad$ Annual income or net profits per farmer type $i$ and for each decade

$\mu_{i j k} \quad$ Gross margins of farmer type $i$, crop activity $j$, and by land type $k$

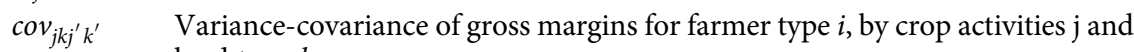
land type $k$. 
$v_{i}$

$\sigma_{i}$

$X_{i j k}$

$L_{i t}^{\text {in }}$

$L_{i t}^{f}$

$L_{i t}^{\text {out }}$

Total variance of gross margins across activities and land types for farmer type $i$

Total standard deviation of gross margins across activities and land types for farmer type $i$

Area located by each farmer type $i$ to each crop activity $j$ (including technology type) and by land type $k$.

Hired in labor for farmer type $i$ and by season $t$

Own family labor used by farmer type $i$ in season $t$, where $L_{i t}^{f i n} \leq f_{i t}$

Own family labor hired out by farmer type $i$ in season $t$, where $L_{i t}^{\text {fout }} \leq f_{i t}$

two growing seasons and we assume that the covariance of income between the two seasons is zero. This implies that expected utility for the year is simply the sum of the expected utilities generated each season.

The symbols $\mu_{i j k}$ and $\operatorname{cov}_{j k j^{\prime} k^{\prime}}$ in equations $2^{\prime}$ and $3^{\prime}$ above are the expected mean and covariance of on-farm gross margins, respectively, for each cropping activity $j$ and by type of land $k$ based on annual observations over each decade. The prime of $j$ (or $k$ ) associates the covariants between all activities adopted in the choice set, respectively. The subscripts $i$ in the mean profits $\left(\pi_{i}\right)$ and standard deviation of gross margins $\left(\sigma_{i}\right)$ represent the three farm types: small, medium, and large. The $j$ cropping activities include the five choice crop activities and by technology types available (see Table 6A.1).

$X_{i j k}, L_{i t}^{\text {fout }}$ and $L_{i t}^{h}$ are choice variables as follows: $X_{i j k}$ is the acreage allocation to each cropping activity and by land type; $L_{i t}^{\text {fout }}$ is own family labor hired out by farmer type $i$ and in month $t$; and $L_{i t}^{h}$ is labor hired in by farmer type $i$ and in month $t$. Fixed parameters include the following: $w_{i t}$ is the going wage rate for hiring in labor, while $w_{i t}^{*}$ is a fraction of the going wage rate for hiring out own family labor by farmer type. We assumed this changed over the decades as increasingly more off-farm employment options grew over time. As such, the value of $w_{i t}^{\star}$ was set at 40 percent, 50 percent, and 60 percent for the 1990, 2000, and 2010 decades across the months; $p_{i j}$ represents the average farm-gate price of each crop by activity $j$ (all in constant 2015 Ghanaian cedi values); $y_{i j}$ represents crop yields by activity $j$ (crop and by technology type). Finally, $c_{i j t}$ represents per unit costs for purchased inputs under each activity $j$ in month $t$ (also in constant 2015 Ghanaian cedi values).

The objective function in equation 1 is subjected to three resource constraints representing an upper bound on the supply of labor, land, and a minimum amount of production to satisfy own consumption for maize, yam, and cassava. In mathematical terms, the resource constraints are as follows:

$$
\sum_{j} \sum_{k}\left[a_{j k t}+a_{j k t}^{h}\left(\bar{y}_{i j k}\right)\right] X_{i j k} \leq L_{i t}^{f}+L_{i t}^{i n}, \forall i t
$$

Where:

$$
L_{i t}^{f} \leq f_{t}-L_{i t}^{\text {out }}
$$

[Labor supply constraint in month $t$ ]

$$
\sum_{j} X_{i j k} \leq a_{i k}, \forall i k
$$

[Land availability constraint by land type] 
Equation (4) is the main labor demand and supply equation-that is, labor required across all production activities and land clearing for new land can be sourced only from own family labor used $\left(L_{i t}^{f}\right)$ and labor hired in $\left(L_{i t}^{i n}\right)$. The term $\alpha_{j t}$ represents labor-use coefficients (person hours) under each cropping activity for land preparation, planting, and weeding. Harvesting and shelling in the field is captured in the separate term $\alpha_{j k t}^{h}$, which is a function of average annual yields $\bar{y}_{i j k}$ each decade by crop, technology, and land type. In the model we also restrict the YMCS (yam-cassava) activity to virgin land only, based on the observed practice of growing yam during the process of clearing land-burning the trees stumps around the yam mounds. These do not change over the decades. Most of the parameter values do not vary by land type except for land-clearing labor (not shown in the table). For virgin land, this is set at fifty-one man-days per hectare for non-yam-cassava crops and none for the YMCS crop mix as this is cultivated without clearing land. The clearing of a previous plot in fallow for three years is assumed to be a quarter of the time required to clear virgin land.

Equation (5) implies that own labor used on the farm each month $\left(L_{i t}^{f}\right)$ cannot exceed the residual of each farm type's adult equivalent household size $\left(f_{t}\right)$ and labor hired out off the farm each month $\left(L_{i t}^{\text {fout }}\right)$. A typical household size was assumed fixed over the decades and equal across the three farm types. Assuming four adults (two males and two females) and two youth, who work 26 days per month, their adult equivalent are calculated as $f_{t}=114.4\left(\right.$ i.e. $26^{\star}\left(2+0.7^{\star} 2+0.5^{\star} 2\right)$ in person days. For simplicity, we assume there is no upper bound for hired labor $\left(L_{i t}^{i n}\right){ }^{2}$

Equation (6) is a simple land constraint that imposes upper limits on total land available on the farm - that is, total cultivated area cannot exceed what the farmer already has access to on the farm as $a_{i k}$ and by land type. The assumption on fixed availability of land type permits us to impose the local circumstances of declining access to virgin and fallowed lands as observed in the Ejura area. Table 6A.2 presents the share of land type to total area cultivated across the decades based on an earlier IFPRI/SARI survey undertaken in the target area in 2013 (IFPRI/SARI 2013). From the table, use of fallowed land has declined significantly over time as farmers increasingly faced a land frontier by the 2010 decade. Only 10 to 27 percent of area cultivated is previously fallowed land, and only 6 to 25 percent is recently cleared virgin land.

While access to credit is often considered as a limiting factor to adoption in developing countries, we chose not to include it except to introduce a cost for using cash to

Table 6A.2. Percent shares in the type of land available by farm type and for each decade (1990-2010)

\begin{tabular}{|c|c|c|c|c|c|c|c|c|c|}
\hline \multirow[t]{2}{*}{ Farm type } & \multicolumn{3}{|c|}{ Large } & \multicolumn{3}{|c|}{ Medium } & \multicolumn{3}{|c|}{ Small } \\
\hline & 1990 & 2000 & 2010 & 1990 & 2000 & 2010 & 1990 & 2000 & 2010 \\
\hline Con & $22 \%$ & $44 \%$ & $65 \%$ & $29 \%$ & $47 \%$ & $66 \%$ & $23 \%$ & $45 \%$ & $67 \%$ \\
\hline Fallon & $37 \%$ & $24 \%$ & $10 \%$ & $56 \%$ & $41 \%$ & $27 \%$ & $62 \%$ & $45 \%$ & $27 \%$ \\
\hline Virgin land & $41 \%$ & $33 \%$ & $25 \%$ & $16 \%$ & $12 \%$ & $8 \%$ & $15 \%$ & $11 \%$ & $6 \%$ \\
\hline
\end{tabular}

Source: IFPRI/SARI Survey (2013).

\footnotetext{
${ }^{2}$ Earlier attempts to restrict it proved redundant given the small-size acreages and thus the small quantity of hired labor demanded when own family labor becomes binding.
} 
purchase inputs, valued here at the current interest rate or $\tau$ in equation (2). The value of $\tau$ varies by farmer type to capture the variance in access based on wealth and farm size: small -30 percent, medium -25 percent, and large- 20 percent. This is kept constant across the decades and is only meant to emphasize the greater difficulty for accessing cash among poorer or small-farm-size households. We chose to ignore access to credit in its traditional form as we are more interested in adoption patterns when land type conditions change, rather than restricting the ability to pay for inputs altogether.

Among the improved technology types in the model, four are introduced across all farm types and across the decades (not shown in the equations), including: improved seeds only (T1); improved seeds and chemical application, e.g., inorganic fertilizer and herbicides (T2); improved seeds, chemical application, and mechanization (T3); and mechanization and improved seeds only (T4). Traditional technologies will be referred to as T0. Although pesticides (or insecticides) can be considered as a chemical application-we impose these across all technology packages for cowpeas (with the exception of traditional technologies) because these are required regardless of the technology type. Additionally, while mechanization in T3 and T4 refers to the use of tractors during land preparation, we also include chemical herbicides under both packages to represent agricultural extensification (as both are labor-saving technologies). Agricultural intensification, on the other hand, refers to improved seeds and fertilizer use only in T1 and $\mathrm{T} 2$, respectively.

Other restrictions on technology use are imposed on yam, cassava, cowpea, and groundnuts based on local practice. For example, the YMCS activity does not use any chemical inputs or mechanization while groundnuts and cowpeas within their respective rotations do not use any fertilizer. Maize is the only crop using fertilizer in its rotation with legumes. From the field interviews, mechanization was very minimal in the 1990s due to its unavailability and high relative cost. Finally, the maize-legume crop rotations are also affected by rotations across the two growing seasons based on the field interviews on local practices. Farmers claimed that typically they would halve the total area allocated to the rotation as illustrated in Figure 6A.1. Basically, farmers break down their area allocated to the rotation in half, growing maize in one plot and a legume in the other half. For the next season, they rotate but sticking to the same legume and cereal (maize in this case). According to them, this helps recover some soil nutrient losses by following such a cereal-and-legume rotation.

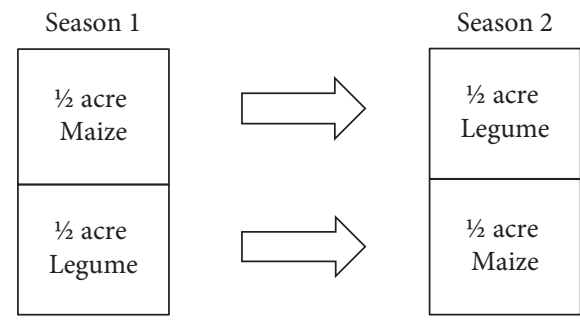

Figure 6A.1. Crop rotations between maize and legume (groundnuts or cowpeas) for a one-acre plot example and between two growing seasons in the Ejura area Source: Based on field interviews by the authors in Ejura. 


\section{Data Sources and Calculations}

Based on an extensive literature review and data sources, including one of the author's own past work in Ghana (see Johnson et al. 2006), input and output coefficients, population, land-use patterns, prices, and crop area allocations, were compiled and reviewed for each of the four decades being analyzed. The data and parameters used in the model are only for the transitional zone and can be made available by the author upon request (johnsonphiri@gmail.com). Here we only present a few key parameters we wish to highlight-yields, means, and co-variance of gross margins.

For yields, a number of assumptions and calculations had to be undertaken in order to not only capture changes in yield variability across decades, but yield differences according to both technology (seeds and fertilizer) and land type (continuous, fallowed, and virgin lands), and accounting for the general decline in yields due to degradation in soil fertility over time.

To capture the effect of technologies such as fertilizer (applied only to maize), a simple quadratic crop response function was specified, calculated from maize yield estimates in the Ejura area by Adjei-Nsiah et al. (2007):

$$
y_{t}(N)=\alpha_{t}+\beta N+\gamma N^{2}, \forall t=1990, \ldots, 2015
$$

Where, $\alpha_{t}=$ is an intercept (known annual base yield), $\beta=$ is a constant slope parameter valued at 33.2, and $\gamma=$ a negative quadratic term valued at -0.185 . For each decade, the baseline yields also vary by the land on which they are being cultivated (continuous, fallowed, or on previous virgin lands) and by the type of seed (traditional or improved). The $N$ variable is weight of inorganic fertilizer applied at five different rates up to a maximum recommended dosage of $90 \mathrm{~kg}$ per hectare: $N=0$ (no fertilizer application such that $y_{t}(0)=\alpha_{t}$ ); $N=0.25$ (one quarter the maximum dosage, or $22.5 \mathrm{~kg} / \mathrm{ha}$ ); $N=0.50$ (one half the maximum dosage, or $45.0 \mathrm{~kg} / \mathrm{ha}$ ); $N=0.75$ (three quarters the maximum dosage, or $67.5 \mathrm{~kg} / \mathrm{ha}$ ); and, $N=1.00$ (the full recommended maximum dosage, or $90.0 \mathrm{~kg} / \mathrm{ha}$ ). Because we also wished to capture declining levels of soil fertility over time, we assumed the base yields in $\alpha_{t}$ declined over time at about 7.2 percent per decade on average.

To allow for a time-series trend in yields and their variability, we had to rely on national level trends given the absence of sufficient time-series data at the local level in Ejura. These trends were adjusted to their base levels in the Ejura region. Combining this information with the fertilizer to yield the response function described above, we estimated the pattern of yield changes over time by the type of seed used and from fallowed lands only. These were then compared with actual observed yields based on interviewee estimates in the field and secondary data sources from the Ministry of Food and Agriculture (MoFA) and United Nations' Food and Agricultural Organization statistical database (FAOSTAT) for consistency.

Final averaged yields across the decades are reported in Table 6A.3. From the table, yields for local seeds are shown to decline over time under a continuous cropping system and reduced fallow as nutrients are mined from the soil. This has actually been occurring in Ejura as fallowed and virgin lands have become increasingly scarce. On the other hand, we assumed the average yield from improved varieties will still rise some (although very slightly) under continuous cropping as new higher-yielding varieties are introduced each year and in spite of the decline in soil fertility. Both seeds perform quite well with the 
Table 6A.3. Maize yields by type of seed and responses to fertilizer

\begin{tabular}{|c|c|c|c|c|c|c|c|c|}
\hline & \multicolumn{2}{|c|}{$\begin{array}{l}\text { No fertilizer } \\
\text { application }\end{array}$} & \multicolumn{4}{|c|}{$\begin{array}{l}\text { S2, with fertilizer (application } \\
\text { rates-\% of maximum dosage } \\
\text { recommended) }\end{array}$} & \multirow{2}{*}{$\begin{array}{l}\text { Ratio } \\
\text { (Seeds) } \\
\text { S2/S1 }\end{array}$} & \multirow{2}{*}{$\begin{array}{l}\begin{array}{l}\text { Ratio } \\
\text { (Fertilizer) }\end{array} \\
100 \% \text { app/ } \\
\text { No app }\end{array}$} \\
\hline & $\mathrm{S} 1$ & S2 & $25 \%$ & $50 \%$ & $75 \%$ & $100 \%$ & & \\
\hline & a & b & & & & c & $\mathrm{b} / \mathrm{a}$ & $c / b$ \\
\hline \multicolumn{9}{|c|}{ Continuously cropped } \\
\hline 1990 & 793 & 1,025 & 1,554 & 1,931 & 2,156 & 2,229 & 1.29 & 2.18 \\
\hline 2000 & 736 & 1,213 & 1,795 & 2,210 & 2,458 & 2,538 & 1.65 & 2.09 \\
\hline 2010 & 683 & 1,402 & 1,984 & 2,399 & 2,647 & 2,727 & 2.05 & 1.94 \\
\hline \multicolumn{9}{|c|}{ Previously fallowed } \\
\hline 1990 & 855 & 1,104 & 1,634 & 2,011 & 2,236 & 2,309 & 1.29 & 2.09 \\
\hline 2000 & 834 & 1,276 & 1,858 & 2,273 & 2,521 & 2,601 & 1.53 & 2.04 \\
\hline 2010 & 794 & 1,439 & 2,021 & 2,435 & 2,683 & 2,763 & 1.81 & 1.92 \\
\hline \multicolumn{9}{|c|}{ Cleared virgin land } \\
\hline 1990 & 855 & 1,104 & 1,634 & 2,011 & 2,236 & 2,309 & 1.29 & 2.09 \\
\hline 2000 & 855 & 1,308 & 1,890 & 2,304 & 2,552 & 2,632 & 1.53 & 2.01 \\
\hline 2010 & 855 & 1,512 & 2,093 & 2,508 & 2,756 & 2,836 & 1.77 & 1.88 \\
\hline \multicolumn{9}{|c|}{ Annual growth (\%) } \\
\hline Continuous & -0.6 & 1.5 & 1.1 & 1.0 & 0.9 & 0.9 & n.a. & n.a. \\
\hline Fallowed & -0.3 & 1.2 & 0.9 & 0.8 & 0.8 & 0.8 & n.a. & n.a. \\
\hline Virgin land & 0.0 & 1.5 & 1.1 & 1.0 & 0.9 & 0.9 & n.a. & n.a. \\
\hline
\end{tabular}

Source: Authors' calculations from model data.

introduction of fertilizer-although the improved variety always outperforms local seeds' response to fertilizer as would be expected. We assume yields on virgin lands to not change over the years for local seeds.

For prices, local prices were cross-checked with those from the Ministry of Food and Agriculture (MoFA) for Ejura. Because prices of vegetables were only a proxy using tomatoes, the prices subsequently were adjusted during model calibration. It was also observed that local prices for yams and cassava fluctuated a lot, and are often lower than the numbers reported. The same is true with yields for both crops, as these are inherently difficult to measure (as tubers). As such, prices for these two commodities were also adjusted during model calibration-especially for the 1980s and 1990s decades. The final prices used in the model are shown in Figure 6A.2, including corresponding estimates of gross margins. The variations in gross margins and prices appear to be quite similar, implying that price variation has been more volatile than yields.

One thing that stands out immediately in Figure 6A.2 is the higher variance in price and gross margins for most of the commodities in the 2000 decade (aside from cowpeas, yams, and cassava). This was a period when food prices rose sharply in the latter half of the 2000 decade. The volatility in prices remained higher than in the 1990s during the more recent decade (2010) for cassava only. Among the five commodities, maize and groundnuts recorded the highest volatility in gross margins in 2000-which explains some of the shifting away from groundnuts to cowpea cultivation in the farm 

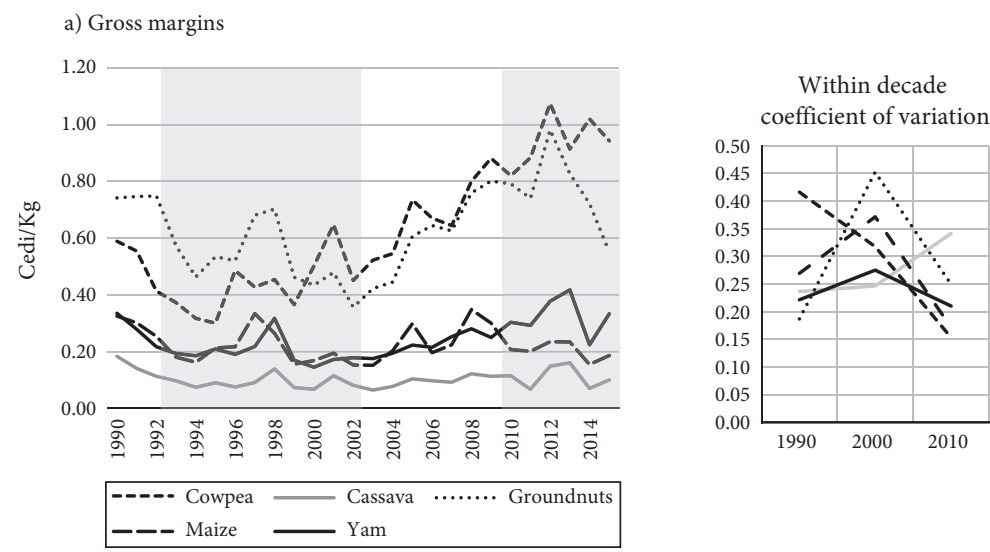

b) Prices
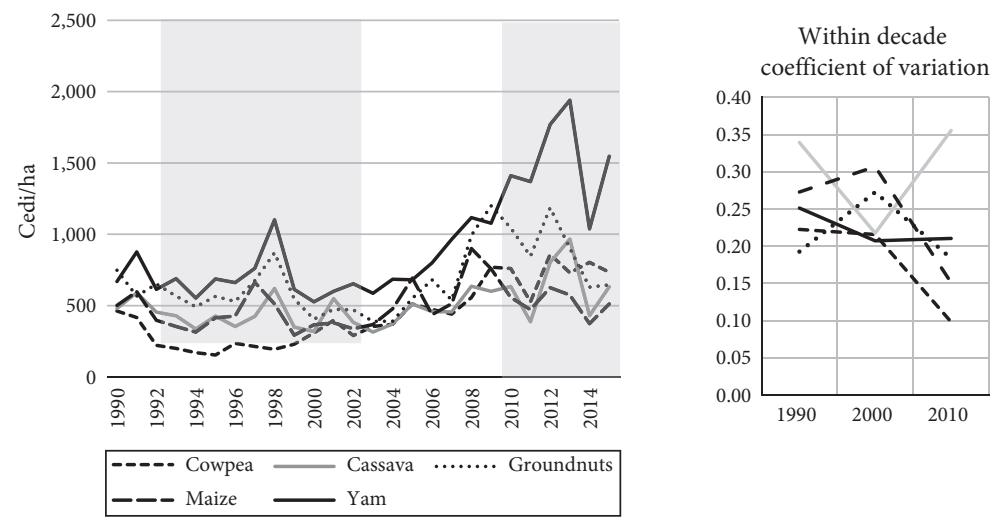

Figure 6A.2. Gross margins and annual price trends in Ejura, 1980-2015 (constant 2015 US\$/kg)

Source: MoFA national monthly price data, 1980-2010. For the more recent years, 2011-15, these are taken from monthly recorded prices in Ejura and adjusted with previous national trends.

model solutions. In general, expected gross margins and their variances also rise with higher-yielding technology and/or land type combinations-which can affect the rate of adoption each decade under risk-averse behavior.

With regard to input costs, wages have grown more significantly since 2000 , essentially more than doubling. We assumed off-farm wages are typically less than the cost of hiring in labor, due to either search costs, or as is more common, leasing out labor at a period when demand for labor is lower and pays less. Nevertheless, to capture recent improvements in road infrastructure and transportation, and therefore access to off-farm employment opportunities in the Ejura area, we allow this wage to rise until it is about equal to the wage for hiring in labor by 2010. Base values for farm sizes and area allocations to crops was derived from both the group interviews of farmers in the Ejura area and data collected by IFPRI in 2012 in the same area. 


\section{References}

Adjei-Nsiah, S., T. W. Kuyper, C. Leeuwis et al. 2007. "Evaluating Sustainable and Profitable Cropping Sequences with Cassava and Four Legume Crops: Effects on Soil Fertility and Maize Yields in the Forest/Savannah Transitional AgroEcological Zone of Ghana.” Field Crops Research 103(2): 87-97.

Amanor, K. S., and O. Pabi. 2007. "Space, Time, Rhetoric and Agricultural Change in the Transition Zone of Ghana.” Human Ecology 35: 51-67.

Brooke, A., D. Kendrick, and A. Meeraus. 1998. GAMS: A User's Guide. Redwood City: The Scientific Press.

Ghana Statistical Service. 1998. Ghana living standards survey data 1998. Accra.

Ghana Statistical Service. 2000. Ghana living standards survey data 2000. Accra.

Ghana Statistical Service. 2005. Ghana living standards survey data 2005. Accra.

Ghana Statistical Service. 2010. Ghana living standards survey data 2010. Accra.

Ghana Statistical Service. 2012. Ghana living standards survey data 2012. Accra.

Hazell, P. B. R., and R. D. Norton. 1986. "Mathematical Programming for Economic Analysis in Agriculture.” New York: Macmillan.

Houssou1, Nazaire, Michael Johnson, Shashidhara Kolavalli, and Collins AsanteAddo. 2017. "Changes in Ghanaian Farming Systems: Stagnation or a Quiet Transformation?" Agriculture and Human Values 35(1): 41-66.

Johnson, M., W. A. Masters, and P. V. Preckel. 2006. "Diffusion and Spillover of New Technology: A Heterogeneous-agent Model for Cassava in West Africa." Agricultural Economics 35(2): 119-129.

Ragasa, C., A. Dankyi, P. Acheampong et al. 2013. "Patterns of Adoption of Improved Maize Technologies in Ghana.” GSSP Working Paper No. 35. Washington, DC: International Food Policy Research Institute. 